\title{
THE STRATEGIC MARKETING PLANNING - GENERAL FRAMEWORK FOR CUSTOMER SEGMENTATION
}

\author{
Alina Elena OPRESCU, Ph.D. student \\ Bucharest University of Economic Studies
}

\begin{abstract}
Any approach that involves the use of strategic resources of an organisation requires a responsible approach, a behaviour that enables it to properly integrate itself into the dynamic of the business environment. This articles addresses in a synthetic manner, the issues of specific integration efforts for customers' segmentation in the strategic marketing planning. The essential activity for any organisation wishing to optimise its response to the market, the customer segmentation will fully benefit from the framework provided by the strategic marketing planning. Being a sequential process, it not only allows time optimisation of the entire marketing activity but it also leads to accuracy of the strategic planning and its stages.
\end{abstract}

Keywords: strategic planning, marketing strategy, customer segmentation, marketing mix, optimisation

JEL Classification: $\mathrm{M}_{19}, \mathrm{M}_{31}$

\section{Literature review}

Strategic planning has developed as part of the marketing activity as a response to demands and challenges coming from the business environment. Issuing an appropriate response for inputs corresponding to environmental factors require a continuous decision-making process that enhances the modality of creative use of all company resources at a certain moment.

This decision-making processes will have a continuous and also elaborated character, not the result of spontaneous mechanisms.

Policy makers from each organisation need to dynamically connect to the reality of the marketing environment, both internal and external. In order to achieve this, the identification of the main evolution coordinates of the environment are the responsibility of marketing researchers.

They allow, through their scientific methodologies and tools, in-depth investigation of all phenomena that occur in the environment, of their dynamics, structured according to the type of analysed elements - elements of microenvironment or macro environment, or elements of the internal environment of organisations. Informational support for the decision-making process determines the actual quality of the approach and certain reaction times of the entire business entity.

However, the possibility of implementing a comprehensive marketing strategy, to enable a real growth for the economic entity will be based not only on decisions developed with a strong support based on information but also on a 
proper strategic planning, the decision-making processes meaning the undergoing of several steps.

The strategic marketing planning is a complex notion that has evolved with the very concept of marketing. Thus, in the 1950s and 1960s, the economic growth was the dominant feature of the external economic environment, therefore the planning processes were directed towards the discovery and exploitation of entrepreneurial opportunities, being characterised by decentralisation (Jain C. Subhash, 2000, p. 1). Managers were focused on major decisions on investments and ways of operating the annual budget. Thus, there were no long-term planning efforts at corporate level.

In the 1970s the situation changed dramatically when company needs changed drastically as a result of changes in the economic environment (4- times increase of energy costs, increased competition, recession, capital crisis etc.). In this new context, the managerial needs regarding the strategic planning went towards a tighter control of limited resources and finding efficient ways of fighting the competition. Planning seen as a function of modern management has become increasingly important with the evolution of complex business relations and microand macro-economic factors.

Thus, at present, strategic planning may be defined as, the systematic process through which an organisation agrees on priorities that are essential to its mission and meet environment demands while providing in the same time the foundation of a commitment among key stakeholders. Strategic planning will guide the acquisition and distribution of resources necessary to achieve these priorities' (Allison Michael, Kaye Jude, 2005, p. 1). This process will take into account the existence of three key dimensions for planning, interrelated dimensions and equally important to the success of organisations: analytical dimension related to techniques, procedures, planning systems and models, organisational dimensions related to the flow of information, structures, processes, management types and organisational culture and behavioural dimension related to the nature and degree of participation and motivation of the managerial team (Bondrea A. Aurelian, Gârdan Daniel Adrian, Geangu Iuliana Petronela, 2010, p. 54-55).

Current context characteristic for the marketing environment of organisations is characterised by the following categories of factors that emphasised the need planning development:

- Globalisation (easier world trade, easier access of competitors to cheap labour, raw materials etc.);

- the free market, existence of an entrepreneurial political environment in many countries;

- Rapid technological innovation, creating new ways to increase competitiveness.

Strategic planning will consider three basic levels necessary in a modern organisation: corporate-level planning, strategic unites-level planning and functional or departmental-level planning.

Accordingly, the three ,layers' of strategic planning have three corresponding strategic approaches - global business strategy of the organisation, specific 
business strategy of the strategic unit and strategy specific to function or department taken into consideration.

In terms of marketing activity, it could be also conceptualised on three levels, thus the role of marketing at corporate level being to provide the broadest perspective on environment of the organisation in order to correctly identify corporate business objectives on long and very long term; at the strategic business units-level, the marketing will play the role of identifying the situation and tools appropriate to implement a strategy to help integrate objectives specific for strategic business unit while at the departmental unit - the marketing activity will meet the needs regarding the concept and implementation of marketing programs for a good short- and medium term functioning of corporate individual organisation forms.

\section{Steps in marketing planning}

In general, marketing planning process consists of the same stages, regardless of the nature of organisation where it is applied (Blythe Jim, Megicks Phil, 2010, p. 16):

A. Analysis - the step when there are identified the defining elements for the current situation of the organisation, both internal and external;

B. Planning- an essential step which involves setting of marketing objective, identification of activities leading to achievement of set objectives, taking into account of their group and according to the elements of marketing mix.

C. Implementation - step that consists in applying the set of specific activities previously identified for achieving the objectives. During this step there are established in detail the time span of activities, their sequence, responsible personnel, pay etc.

D. Control - this step is not exactly the last one because it is actually is a sort of audit and control and it exists in one-way or another throughout the entire planning process. It is aimed primarily the feedback at internal or external environment- level of the organisation as a response of the implementation of all the other previous steps. If special circumstances require reconsideration of activities, deadlines, responsibilities, even budgetary decisions in order to ensure the achievement of set objectives, there can be re-establish the set of activities, their content, sequence etc.

However, the steps presented above may be customised according to: specific industry, scale of the marketing activity developed by the organisation, history on the market, cyclicity of the production process, specific elements and external influencing factors.

As mentioned above, the marketing activity has the purpose of achieving specific objectives depending on the level of planning: corporate, strategic business unit or functional-departmental. In this context, experts talk about marketing strategies, seen as ways to achieve marketing objectives, organically subordinated to the organisation as a whole. Thus, the marketing strategy will represent an essential component of organisations marketing policy representing real ways of 
achieving the objectives: market strategy, product strategy, marketing strategy etc. (Florescu Constantin, Mâlcomete Petre, Pop Al. Nicolae (coordinators), 2003, p. 669).

Worldwide and at organisation-level, the marketing policy will define the broad vision necessary to fulfil corporate objectives - this will be applied in each business strategic unit as a marketing strategy, given the specific objectives, for that specific market. In turn, the operationalization of the market strategy from the business strategic unit-level will be performed by means of marketing mixes tailored for each case, with specific objectives and activities.

Therefore, it becomes obvious the relation between the two concepts strategic planning and marketing strategy. Planning will represent the process by which it will be effectively implemented and properly defined the way to go in order to achieve the objectives - strategy. The output of the planning process will be represented by action plans, one of the steps presented above - implementation representing the highlight of the sum of activities and for the strategy itself.

\section{Customer segmentation and its role in the strategic planning of the organisation}

Substantiation of the marketing strategy will take into account the segmentation process of customers, seen as a fundamental element in the context of marketing strategic planning. Customer segmentation will represent an essential process for the correct substantiation of the marketing strategy and the realisation of an appropriate strategic planning.

In the figure below, you can highlight the place it occupies segmentation with respect to other processes within the marketing planning. 


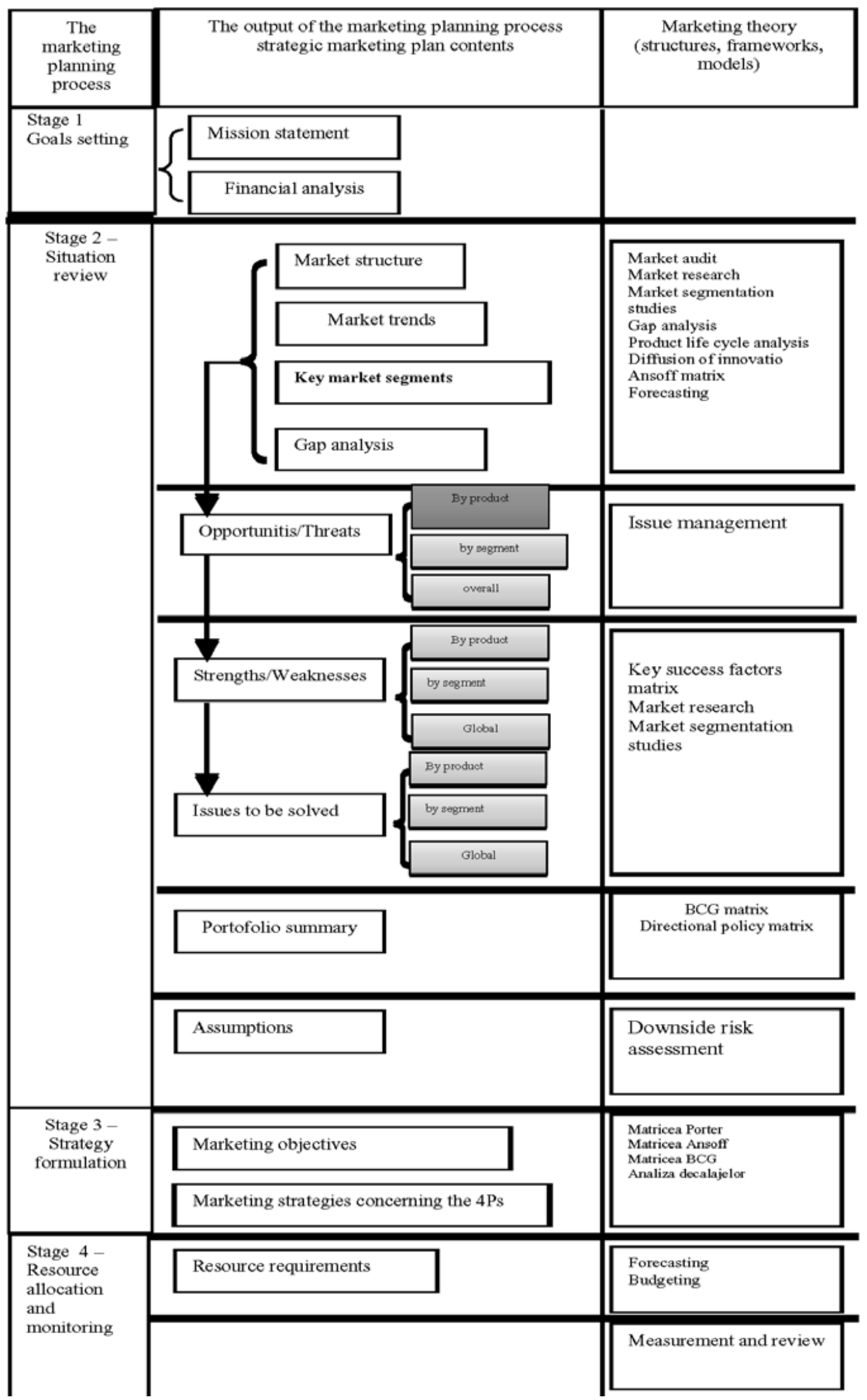

Figure nr. 1. The stages of the marketing planning and the integration of the segmentation within their adjacent concepts and instruments

Source: adaptation from McDonald Malcom, Malcom McDonald on Marketing Planning, Kogan Page, London, 2008, ISBN: 978-0-7494-5149-3, p. 47 
Customer segmentation allows any organization to direct its limited resources to the most promising opportunities through customer sorting within groups prioritized and managed easily.

Segmentation process may begin with a "mapping" of the market. Making a "map" of the market involves defining the value chain and distribution between supplier and end consumer, taking into account the various mechanisms on the market purchasing processes, including those played by the "influencers" or those who advise consumers or affect in any way the result of the buying process.

They are on the market map where transactions occur. By identifying "tracks" of transactions in the market in which an organization operates, is likely to identify the most important routes as key junctions where decisions are made and segmentation occurs. Clearly, the types of customers or segments should be linked to distinctive competence of the firm and its competitors, that if you want to create a true competitive advantage. In fact, the goal of segmentation should be to find the best ways to match the capabilities of the organization with customer groups that share similar needs.

Many experts, including the renowned Professor Malcolm McDonald, believe that segmentation should be a process that will take place before the strategic planning as the correct definition of existing market segments, the organization will be able to: (Malcolm McDonald, 2008, p. 59):

- Identify better the market share owned;

- Measure better the growth;

- Correctly identify target customers;

- Recognize relevant competitors;

- Formulate marketing objectives and strategies

It should be noted that the correct definition of customer segments facing the organization in their market space, is a process that really should be performed at the beginning of strategic planning at the strategic business unit or department functional. When we discuss corporate planning at the global level of the whole organization, it may happen that customer and market segmentation does not represent an objective necessity in the beginning of the planning process. Substantiation of overall, corporate objectives involves identifying targets defined by levels of profitability and efficiency of investment that addresses the entire business unit of the organization, regardless of the number of markets or product lines or separate services it operates with,

Substantiation of marketing objectives specific to strategic marketing planning at the strategic business units requires in exchange knowledge and correct identification of all existing customer segments in the market, because all marketing activities will be customized based on the profile of these segments.

Segmentation will consist in identifying homogeneous groups of customers in terms of needs, products and/or services consumed, of the methods of their choice, consumption habits, etc.

Most organizations will have a range of approaches to segmentation that will materialize in the form of archetypes as shown in the figure below. 


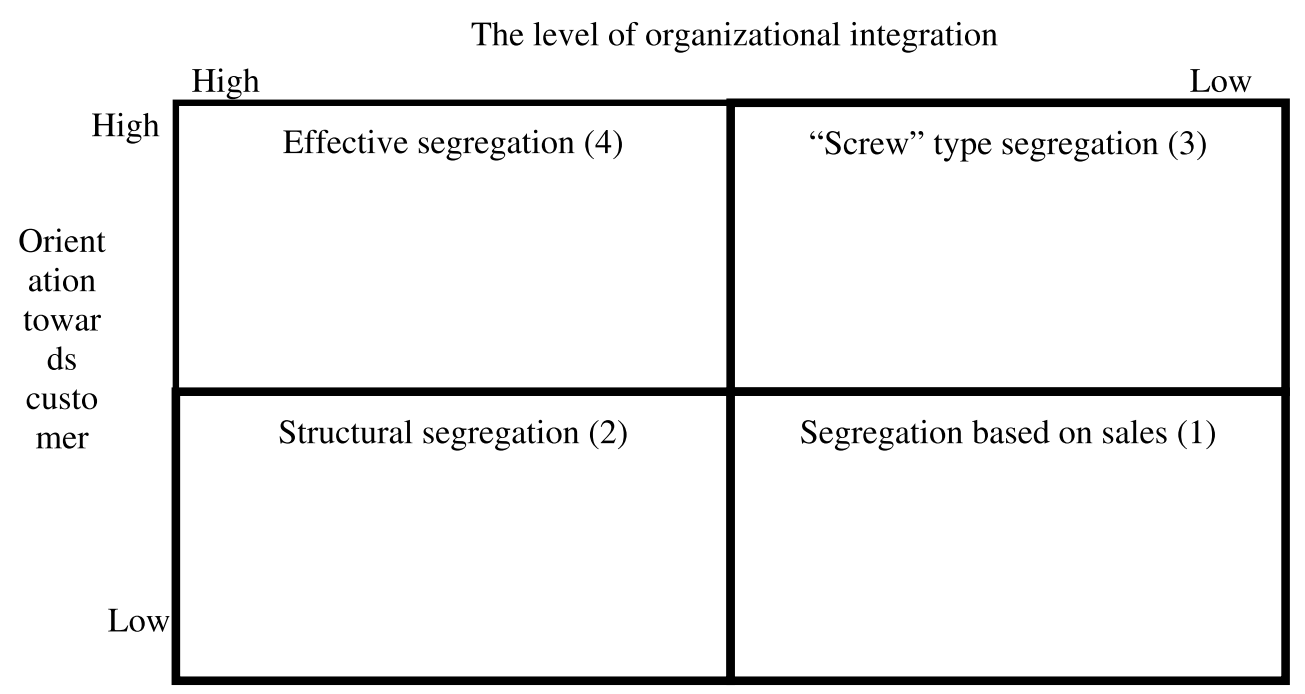

Figure nr. 2. Archetypes of segmentation within the companies

Source: Jenkins Mark, McDonald Malcolm, Market segmentation: organizational archetypes and research agendas, European Journal of Marketing, vol. 31, no. 1, 1997, p. $17-32$

The four types of segmentation are global "models" that companies will deploy depending on the weight of the two criteria considered: the level of integration in terms of organizational of the segmentation model chosen and the level of customer orientation. Thus, the four models of segmentation consider the following characteristics: (McDonald Malcolm, Dunbar Ian, 2004, p. 46).

Segmentation based on sales - Is an organizational archetype, which involves market segmentation based on the way it is organized by sales, which does not always reflect customer groups with specific characteristics and needs. Usually this type of segmentation does not reflect the priorities of the organization viewed as a whole, is based internally.

Structural segmentation - Involves defining "segments" of customers depending on how the organization is structured. This segmentation is often geared towards production and sales being incorporated in all the structures and processes of the organization.

"Screw" type segmentation - Implies a segmentation that uses a strong customer focus, being used customer information already available within the organization such as the location of purchase, behaviour patterns, preferences for products etc. This information will be combined with the external classification systems that align customer base with certain socio-economic profiles. This type of segmentation will be close to that based on sales, as it is limited to a number of functional areas within the organization and is not embedded in the organization viewed as a whole. Often this type of segmentation will be used for promotional campaigns as needed to target a specific group of consumers, niche, so although it 
is very focused on consumers, it will not allow the redefinition of business processes across the organization.

Effective segmentation - Will combine both a high level of integration within the organization and the customer focus. In this segmentation, the organization is able to use a range of customer information to develop a set of defined segments. However, unlike the previous type, the organization will integrate these segments across key functional activities. Thus, in fact, this type of segmentation represents the actual segmentation that provides the work basis for both promotional activities and for all other processes and operations of the organization. In this case, we can speak of a customization of the marketing mix for each segment.

The customer segmentation will be a constant effort that in the strategic business units or functional level of marketing departments will effectively overlap with the planning. Each new effort of planning and foundation of marketing strategy will take into account in advance the customer segmentation process, following that the concrete results of the foundation of marketing strategy to be found those new inputs for situational analysis and a new state of the market in terms of segmentation. Here he will be able to discuss a permanent cycle segmentation - planning - foundation of strategy - segmentation.

\section{Conclusions}

Proper development of tomorrow's companies found their solid substrate in creating new models based on strategic planning. Nothing can be left to chance. No matter how great may be the potential of an organization, regardless of the nature and amount of resources available and the number and quality of existing opportunities in the external environment, the use of rigorous principles of strategic planning will always be a strong competitive advantage. Planning manages to print consistency and continuity of marketing activity, ensuring a healthy cycle of adjustment process to the marketing environment and allows naturally emphasize of the opportunities in conjunction with strengths.

Strategic planning involves judicious engagement of all strategic resources of companies and their long-term orientation towards development of strategies relating to environmental elements of marketing. Note the opportunity for any current economic entity to investigate and develop the potential of creating the marketing network, an expression of the principles of relationship marketing. Thus, strategic planning seen in the context of relationship marketing would only potentiate the possibilities offered by this concept. Currently, strategic orientation specific to relationship marketing is far from being outdated, in fact technological evolving and IT tools available in conjunction with the development of social networks offering new directions of evolution for both the concept itself and for its operational modalities (Gârdan Daniel Adrian, 2011, p. 86-87).

Customer segmentation is a natural expression of the principles of strategic planning. Made in the development of relationship marketing strategies, segmentation is the basis for a coherent strategy to enable effective positioning of organizations in relation to segments that have an interest in developing long-term relationships. 
This strategy takes into account the major networking features of target groups, their ability to answer, the specific and dynamics of interests manifested.

In an extended term vision, strategic planning and segmentation process shape for any organization the complex mechanism by which it will emulate the development directions of its business environment, the directions of action necessary to optimize competitive potential.

\section{REFERENCES}

Allison Michael, Kaye Jude (2005), Strategic Planning for Nonprofit Organizations, second edition, New Jersey: John Willey \& Sons Inc.

Bondrea A. Aurelian, Gârdan Daniel Adrian, Geangu Iuliana Petronela (2010), The role of strategic planning in relationship marketing, Annals of Spiru Haret University, Economic Series, vol. 1, issue 4, pp. 53-60.

Blythe Jim, Megicks Phil (2010), Marketing planning: strategy, environment and context, Pearson Education Limited, Harlow.

Cetină Iuliana (coord.) (2009), Marketingul serviciilor. Fundamente şi domenii de specializare, Editura Uranus, București.

Dumitru Ionel (2004), Marketing strategic. O abordare în perspectiva globalizării, Bucureşti, Uranus.

Florescu Constantin, Mâlcomete Petre, Pop Al. Nicolae (2003), Marketing dicționar explicativ, Editura Economică, București.

Gârdan Daniel Adrian (2011), The new perspectives in relationship marketing conceptualization, Annals of Spiru Haret University, Economic Series, vol. 2(11), issue 4, pp. 81-9.

Jain C. Subhash (2000), Marketing Planning and Strategy, $6^{\text {th }}$ edition, SouthWestern College Publishing.

Jenkins Mark, McDonald Malcolm (1997), Market segmentation: organizational archetypes and research agendas, European Journal of Marketing, vol. 31, nr. 1, pp. 17-32.

McDonald Malcom (2008), Malcom McDonald on Marketing Planning, London: Kogan Page.

McDonald Malcom, Dunbar Ian (2004), Market Segmentation - How to do it, How to profit from it, Elsevier Butterworth-Heinemann 
